\title{
Assimilation of ASCAT near-surface soil moisture into the SIM hydrological model over France
}

\author{
C. Draper ${ }^{1, *}$, J.-F. Mahfouf ${ }^{1}$, J.-C. Calvet ${ }^{1}$, E. Martin ${ }^{1}$, and W. Wagner ${ }^{2}$ \\ ${ }^{1}$ CNRM/GAME (Météo-France, CNRS), URA 1357, Toulouse, France \\ ${ }^{2}$ Institute of Photogrammetry and Remote Sensing, Vienna University of Technology, Wien, Austria \\ *now at: NASA GSFC/GEST, Greenbelt, USA
}

Received: 11 May 2011 - Published in Hydrol. Earth Syst. Sci. Discuss.: 1 June 2011

Revised: 24 October 2011 - Accepted: 12 November 2011 - Published: 21 December 2011

\begin{abstract}
This study examines whether the assimilation of remotely sensed near-surface soil moisture observations might benefit an operational hydrological model, specifically Météo-France's SAFRAN-ISBA-MODCOU (SIM) model. Soil moisture data derived from ASCAT backscatter observations are assimilated into SIM using a Simplified Extended Kalman Filter (SEKF) over 3.5 years. The benefit of the assimilation is tested by comparison to a delayed cut-off version of SIM, in which the land surface is forced with more accurate atmospheric analyses, due to the availability of additional atmospheric observations after the near-real time data cut-off. However, comparing the near-real time and delayed cut-off SIM models revealed that the main difference between them is a dry bias in the near-real time precipitation forcing, which resulted in a dry bias in the rootzone soil moisture and associated surface moisture flux forecasts. While assimilating the ASCAT data did reduce the root-zone soil moisture dry bias (by nearly $50 \%$ ), this was more likely due to a bias within the SEKF, than due to the assimilation having accurately responded to the precipitation errors. Several improvements to the assimilation are identified to address this, and a bias-aware strategy is suggested for explicitly correcting the model bias. However, in this experiment the moisture added by the SEKF was quickly lost from the model surface due to the enhanced surface fluxes (particularly drainage) induced by the wetter soil moisture states. Consequently, by the end of each winter, during which frozen conditions prevent the ASCAT data from being assimilated, the model land surface had returned to its original (dry-biased) climate. This highlights that it would be more effective to address the precipitation bias directly, than to correct it by constraining the model soil moisture through data assimilation.
\end{abstract}

Correspondence to: C. Draper

(clara.draper@nasa.gov)

\section{Introduction}

The last decade has seen considerable interest in the possibility of improving hydrological and meteorological model forecasts by assimilating remotely sensed near-surface soil moisture data (Houser et al., 1998; Crow and Wood, 2003; Reichle and Koster, 2005; Balsamo et al., 2007; Drusch, 2007). This interest has motivated recent advances in soil moisture remote sensing, from both purpose designed Lband sensors (Kerr et al., 2001; Entekhabi et al., 2004), and preexisting suboptimal C- and X-band sensors (Wagner et al., 1999; Owe et al., 2001). As a result remotely sensed nearsurface soil moisture data are available for the first time with sufficient quality and legacy to be used in operational models, and in particular EUMETSAT is now providing the first operationally supported remotely sensed near-surface soil moisture product. This product, which is derived from Advanced Scatterometer (ASCAT) microwave radiometer observations, is now being assimilated into the UK Met Office's operational NWP system (Dharssi et al., 2011), and will soon be introduced into ECMWF's system (de Rosnay et al., 2009). At the Met Office, assimilating the ASCAT data has been shown to improve both the model soil moisture analyses (relative to in situ soil moisture data over the US), and screenlevel temperature and humidity forecasts in some regions (Dharssi et al., 2011).

This study seeks to determine whether an operational hydrological model, specifically Météo-France's SAFRANISBA-MODCOU (SIM) model, might also benefit from the assimilation of these ASCAT near-surface soil moisture observations. SIM is a three-part model, consisting of (i) a lowlevel atmospheric analysis (the Système d'Analyse Fournissant des Renseignements Atmosphériques à la Neige; SAFRAN), which provides the forcing for (ii) a land surface model (Interactions between Surface, Biosphere, and Atmosphere; ISBA), which in turn provides surface moisture fluxes to (iii) a hydrogeological model (MODCOU),

Published by Copernicus Publications on behalf of the European Geosciences Union. 
which provides forecasts of aquifer levels and streamflow. SIM is run operationally at Météo-France in near-real time, with a three hour data cut-off, which allows observations from approximately 1200 automatic weather stations to be used in the SAFRAN atmospheric analysis. The output from the near-real time SIM is used for water resource monitoring (e.g. see http://climat.meteofrance.com/chgt_climat2/ bilans_climatiques), and to provide the initial conditions for an ensemble streamflow prediction system that will be used for operational flood forecasting (Thirel et al., 2010).

In addition to the near-real time stream, SIM is also run in delayed mode, using additional observations from 3000 climatological observing stations that report once-monthly. Evaluation studies based on this delayed cut-off stream of SIM have shown that the SAFRAN analysis provides accurate meteorological variables for forcing the ISBA land surface model (Quintana-Seguí et al., 2008; Vidal et al., 2010), resulting in accurate forecasts of the spatial and temporal variability of observed water fluxes and streamflow (Habets et al., 2008). However, the near-real time (operational) SAFRAN analysis is known to be less accurate. To prevent the near-real time SAFRAN errors from accumulating in the model land surface, the ISBA state variables in the near-real time SIM system are updated once a month with the corresponding delayed cut-off ISBA states.

In this study, ASCAT surface soil moisture observations from January 2007 to May 2010 are assimilated into a research copy of the near-real time SIM model using a Simplified Extended Kalman Filter (SEKF). The potential benefit of the assimilation is first tested by comparison to in situ soil moisture observations from the SMOSMANIA monitoring network in south France. However, an evaluation based on in situ soil moisture only is limited by representativity differences between the in situ and modeled soil moisture, and so will only be informative of the temporal behaviour of the modeled soil moisture. In situ soil moisture observations are also greatly limited by their spatial coverage: for example the SMOSMANIA monitoring network used here observes at just 12 locations.

In response to these shortcomings, Crow et al. (2009) and Bolten et al. (2010) instead evaluate the impact of assimilating near-surface soil moisture by determining whether the assimilation can correct the model soil moisture for errors applied to the precipitation forcing. A similar approach has been taken here, by evaluating the ASCAT assimilation (into the near-real time SIM stream) against the delayed cutoff stream, which is identical except for its more accurate SAFRAN analysis. This allows the evaluation to be extended to the full model domain, while also allowing variables other than soil moisture to be assessed, including the surface moisture fluxes which are typically of greatest interest to model users. In contrast to Crow et al. (2009) and Bolten et al. (2010), the best atmospheric data available to the near-real time SIM model are used here, and the results are tested against more accurate forcing that become available later on.
Consequently, the benchmark for evaluating success in this experiment is set rather high, and the results directly measure to the benefit of the assimilation to the operational model.

\section{Data and methods}

\subsection{The SIM hydrological model}

SIM (Habets et al., 2008) is run at approximately $0.07^{\circ}$ resolution over France. The SAFRAN (Quintana-Seguí et al., 2008) analyses of the low-level atmosphere are performed every $6 \mathrm{~h}$, and then the 6-hourly analyses are interpolated onto hourly time-steps and used to force ISBA. ISBA (Noilhan and Planton, 1989; Noilhan and Mahfouf, 1996) then outputs hourly estimates of the land surface states, and the exchanges of heat and moisture between the low-level atmosphere, vegetation, and soil. The three layer version of ISBA (Boone et al., 1999) is used in SIM. Finally, MODCOU (Ledoux et al., 1989) is run once daily, to compute the daily evolution of aquifer storages and three-hourly streamflow forecasts.

\subsection{ASCAT remotely sensed soil moisture}

ASCAT is a real aperture backscatter radar observing at $5.255 \mathrm{GHz}$ (C-band), with approximately $25 \mathrm{~km}$ resolution. It orbits on EUMETSAT's Meteorological Operational (MetOp) satellite, which was launched in 2007 to replace the ageing European Remote Sensing (ERS) satellites. MetOp is in a sun-synchronous orbit, with equator crossing times of approximately 09:30 (descending overpass) and 21:30 (ascending overpass) local time. ASCAT provides good spatial coverage, observing approximately $80 \%$ of the globe each day.

Soil moisture estimates are derived from ASCAT radar backscatter coefficients using the empirical change detection approach developed at the Vienna University of Technology (TU-Wien) by Wagner et al. (1999). This approach is based on the assumption that over a long data record, the highest observed reflectivity can be equated to the maximum soil moisture, while the lowest reflectivity can be equated to the minimum soil moisture, and a linear relationship can be used to interpolate the values in between. For full details refer to Wagner et al. (1999) and Naeimi et al. (2009).

The output from the change detection method is an observation loosely referred to as the "surface degree of saturation" (SDS), and defined by:

$\mathrm{SDS}=\left(w_{\mathrm{sfc}}-w_{\min }\right) /\left(w_{\max }-w_{\min }\right)$

where $w_{\mathrm{sfc}}$ is the moisture in the near-surface soil layer, and $w_{\min }$ and $w_{\max }$ are the minimum and maximum $w_{\text {sfc }}$ occurring at that location. C-band microwave observations are sensitive to soil moisture in a thin surface layer, of up to $1 \mathrm{~cm}$ depth, hence the SDS relates only to this thin surface 
layer. The SDS is reported exclusively in percentage units here, to avoid confusion with volumetric $\left(\mathrm{m}^{3} \mathrm{~m}^{-3}\right)$ measures of soil moisture. Note that the SDS is localised, in that equivalent values at different locations do not necessarily indicate equivalent soil moisture, due to spatial differences in the soil moisture bounds.

In response to differences in the ERS and ASCAT observing behaviour, the change detection model parameters used in the ASCAT retrieval algorithm were recently updated (Wagner et al., 2010) to use parameters derived from the ASCAT data record, rather than the ERS values that were initially adopted for ASCAT (Naeimi et al., 2009). This update has further improved the soil moisture observations retrieved from ASCAT, resulting in excellent agreement with other soil moisture estimates. For example, Brocca et al. (2010b) found correlations and anomaly correlations of 0.67 and 0.58 against in situ data in Italy (one site, 13 months) and of 0.75 and 0.60 against modeled estimates (six sites, 13 months), while Brocca et al. (2010a) calculated a mean correlation of 0.65 against in situ data throughout Europe (14 sites, 2 years at most locations) and 0.76 against modeled estimates (20 sites, 2 years).

The ASCAT level 2 surface degree of saturation (SM OBS1) product supplied by TU-Wien has been used here. This product includes the aforementioned update to the change detection model parameters. Since there is some evidence that scatterometer observations taken in the evening are less accurate than early morning observations (Wagner et al., 1999; Albergel et al., 2009), and since there is a spurious relationship in ISBA between the near-surface and rootzone soil moisture after periods of active evapotranspiration (Draper et al., 2011), only the descending overpass ASCAT observations have been used here.

Observations of densely vegetated regions have been removed, based on an ASCAT estimated soil moisture error (provided with the ASCAT data) threshold of $20 \%$. Additionally, observations with an urban fraction greater than $15 \%$ in the ECOCLIMAP database (Masson et al., 2003) have been removed, as have observations with a topographic complexity flag (provided with the ASCAT data) greater than $15 \%$, and/or a wetland fraction (provided with the ASCAT data) greater than $5 \%$.

The remaining data were projected from the $0.125^{\circ}$ Discrete Global Grid used by TU-Wien to the $\sim 0.07^{\circ}$ SIM grid using a nearest neighbour approach. Observations of frozen surface conditions, temporary surface water, or snow-cover were initially identified based on the probabilistic surface state flag provided with the ASCAT data. However an initial investigation revealed that this probabilistic method did not reliably remove the occurrence of surface freezing. Frozen surface conditions manifest in the data as anomalously low soil moisture observations, which can have a significant detrimental impact on the assimilation. Consequently, an additional screening for frozen surface conditions has been applied, by excluding the ASCAT data whenever SIM forecasts nonzero frozen near-surface soil moisture. Where the above data processing resulted in less than 100 observations for a model grid cell (less than $10 \%$ coverage over the 3.5 year study period) the remaining data have not been used.

The ASCAT data were initially converted to volumetric soil moisture by inverting Eq. (1), using the soil moisture bounds from the near-real time SIM model. However, even though this scaled the ASCAT data to match the SIM $w_{1}$ range, there were still substantial differences between the ASCAT and SIM soil moisture values, due to differences in the shape of their distributions. For the 3.5 year study period, the mean across the domain of the absolute difference at each grid cell was $0.016 \mathrm{~m}^{3} \mathrm{~m}^{-3}$. On average, ASCAT was drier than SIM, with a mean (and standard deviation) of $0.229 \mathrm{~m}^{3} \mathrm{~m}^{-3}\left(0.070 \mathrm{~m}^{3} \mathrm{~m}^{-3}\right)$, compared to $0.236 \mathrm{~m}^{3} \mathrm{~m}^{-3}$ $\left(0.073 \mathrm{~m}^{3} \mathrm{~m}^{-3}\right)$ for SIM. Consequently, the ASCAT data were rescaled to better match the near-real time SIM climatology prior to the assimilation, using the CDF-matching technique of Reichle and Koster (2004). This effectively removed the differences in the mean and standard deviation of the ASCAT and SIM soil moisture, and the resulting values for the rescaled ASCAT $w_{1}$ are the same as reported above for SIM.

\subsection{The SMOSMANIA in situ observations}

The SMOSMANIA network (Calvet et al., 2007; Albergel et al., 2008) consists of 12 soil monitoring stations, spanning between the Mediterranean and Atlantic coasts in southwest France, and spaced approximately $45 \mathrm{~km}$ apart. At each SMOSMANIA site the near-surface soil moisture is observed at $5 \mathrm{~cm}$ below the surface. In the comparisons below, the near-surface SMOSMANIA observations have been compared to the ASCAT and SIM near-surface soil moisture time series, both of which relate the approximately the uppermost $1 \mathrm{~cm}$ of soil. Time series of near-surface soil moisture from SMOSMANIA and from ASCAT and SIM show similar scales of temporal variability, indicating that despite the difference in their depths, they can be reasonably intercompared. In contrast, the deepest soil moisture sensors at the SMOSMANIA sites observe at $30 \mathrm{~cm}$, much shallower than the root-zone soil moisture depths used in ISBA (approximately $1 \mathrm{~m}$ ), and the time series from each are qualitatively very different. Consequently, the SMOSMANIA data has been compared to the SIM (and ASCAT) near-surface soil moisture only.

\subsection{The simplified extended Kalman filter}

he SEKF was initially formulated by Balsamo et al. (2004) and Mahfouf et al. (2009) for use in NWP. The equations for the $i$-th model state forecast and update, occurring at time $t_{i}$ (in hours), are:

$\mathbf{x}^{b}\left(t_{i}\right)=\mathcal{M}_{i-1}\left[\mathbf{x}^{a}\left(t_{i-1}\right)\right]$ 
and

$\mathbf{x}^{a}\left(t_{i}\right)=\mathbf{x}^{b}\left(t_{i}\right)+\mathbf{K}_{i}\left(\mathbf{y}^{o}\left(t_{i}+24\right)-\mathcal{H}_{i}\left[\mathbf{x}^{b}\left(t_{i}\right)\right]\right)$

where $\boldsymbol{x}$ indicates the model state, and $\boldsymbol{y}$ is the observation vector. The superscripts $a, b$, and $o$ indicate the analysis, background, and observations, respectively. $\mathcal{M}$ is the nonlinear state forecast model, and, $\mathcal{H}$ is the nonlinear observation operator. For each model grid cell, ISBA partitions soil moisture into three variables: the near-surface soil moisture ( $w_{1}$; defined over the depth of bare soil evaporation), the root-zone soil moisture $\left(w_{2}\right.$; defined over the depth of transpiration), and the deep-layer soil moisture ( $w_{3}$; representing long term surface moisture storage). In these experiments the state update vector consisted of $w_{1}$ and $w_{2}$. The observations occurred $24 \mathrm{~h}$ after the analysis time, and $\mathcal{H}$ was a 24 -h integration of the forecast model, followed by conversion to the observation equivalent variable $\left(w_{1}\right)$. The impact of $w_{2}$ on $w_{1}$ increases with time, and a 24-h forecast length was chosen for the observation operator, as a compromise between a long enough forecast that $w_{2}$ has a reasonable impact on $w_{1}$, and short enough that the forecast can be linearised without significant loss of accuracy.

$\mathbf{K}$ is the Kalman gain, given by:

$\mathbf{K}_{i}=\mathbf{P} \mathbf{H}_{i}^{T}\left(\mathbf{H}_{i} \mathbf{P} \mathbf{H}_{i}^{T}+\mathbf{R}_{i}\right)^{-1}$

where $\mathbf{H}$ is the linearisation of $\mathcal{H}$, obtained by finite differences, and $\mathbf{P}$ and $\mathbf{R}$ are the covariance matrices of the model background and observation errors, respectively.

The traditional EKF evolves the background error covariance matrix through a forecast and analysis cycle, while for the simplified EKF P is instead assumed to have a constant value at the start of each assimilation cycle. However, some temporal evolution of $\mathbf{P}$ is obtained by the inclusion of a model integration in $\mathcal{H}$, and consequently Draper et al. (2009) found that for assimilating near-surface soil moisture into ISBA, the analysed soil moisture generated by the EKF and the SEKF are not substantially different. Hence the simplified EKF was used here, since it is easier to implement. Finally, the assimilation is performed as an individual 1-D assimilation at each model grid, since ISBA does not model horizontal exchanges.

\subsection{The assimilation experiment}

Three simulations of SIM from January 2007 to May 2010 are compared in this paper, and each is summarised in Table 1. For the assimilation of the ASCAT data, referred to as SIM_ASCAT, ISBA was forced with the near-real time (NRT) SAFRAN analysis. The performance of SIM_ASCAT is bench-marked against the performance of an ISBA openloop forced with the NRT SAFRAN analysis, and referred to as SIM_NRT. In Sect. 3.3, the assimilation is evaluated by comparison to an open-loop ISBA simulation generated with the more accurate delayed cut-off (DEL) SAFRAN
Table 1. Details of each SIM simulation.

\begin{tabular}{lcc}
\hline & $\begin{array}{c}\text { SAFRAN } \\
\text { forcing }\end{array}$ & $\begin{array}{c}\text { Assimilated } \\
\text { data }\end{array}$ \\
\hline SIM_DEL & DEL & none \\
SIM_NRT & NRT & none \\
SIM_ASCAT & NRT & ASCAT SDS \\
\hline
\end{tabular}

analysis, referred to as SIM_DEL. For the SIM_ASCAT and SIM_NRT experiments, ISBA was initialised and forced with archived fields from Météo-France's near-real time SIM chain, while the SIM_DEL ISBA output was extracted directly from Météo-France's archives.

For the SIM_ASCAT assimilation, the observation error variances were based on the (temporally variable) error estimates provided with the ASCAT SDS data, which are obtained by calculating the sensitivity of the change detection model to noise in the ASCAT backscatter observations and model parameters. This is the first study to make use of these error estimates, and an initial investigation confirmed that they have some skill in detecting errors in the ASCAT soil moisture.

The ASCAT estimated errors are provided in SDS units and are relative to the ASCAT soil moisture climatology. Consequently, they were linearly rescaled to be consistent with the model soil moisture climatology, by multiplication by the ratio of the standard deviations of the SIM_NRT $w_{1}$ and the ASCAT SDS. The original ASCAT SDS error estimates ranged between 3.5 and $20 \%$ (since observations with an error greater than $20 \%$ were screened out), with a median value of $9.0 \%$. The rescaled error estimates ranged between 0.02 and $0.20 \mathrm{~m}^{3} \mathrm{~m}^{-3}$, with a median value of $0.05 \mathrm{~m}^{3} \mathrm{~m}^{-3}$. This median value is consistent with errors typically expected for remotely sensed soil moisture, and is slightly higher than the average root mean square difference of $0.04 \mathrm{~m}^{3} \mathrm{~m}^{-3}$ between the assimilated ASCAT data and the SMOSMANIA near-surface soil moisture observations described in Sect. 2.3.

The background error covariance matrix was based on that used by Draper et al. (2011) to assimilate AMSR-E nearsurface soil moisture observations into a two-layer version of ISBA: $\mathbf{P}$ was assumed diagonal, and the $w_{1}$ and $w_{2}$ error standard deviations were set at $0.5 \times\left(w_{\mathrm{fc}}-w_{\text {wilt }}\right)$ and $0.2 \times\left(w_{\mathrm{fc}}-w_{\text {wilt }}\right)$, where $w_{\mathrm{fc}}$ and $w_{\text {wilt }}$ are the soil moisture at field capacity and wilting, respectively. These values generate mean error standard deviations close to 0.04 and $0.02 \mathrm{~m}^{3} \mathrm{~m}^{-3}$, for $w_{1}$ and $w_{2}$, respectively.

\section{Results and discussion}

Before presenting the assimilation results, the temporal agreement between the ASCAT SDS and the SIM 


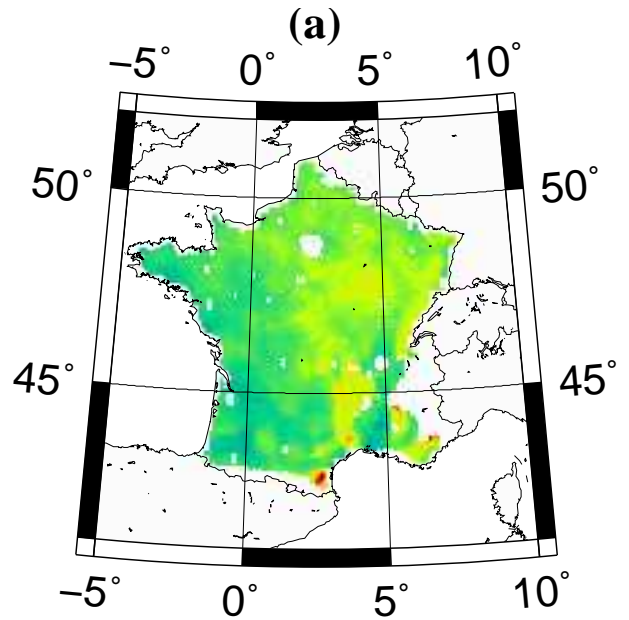

(b)
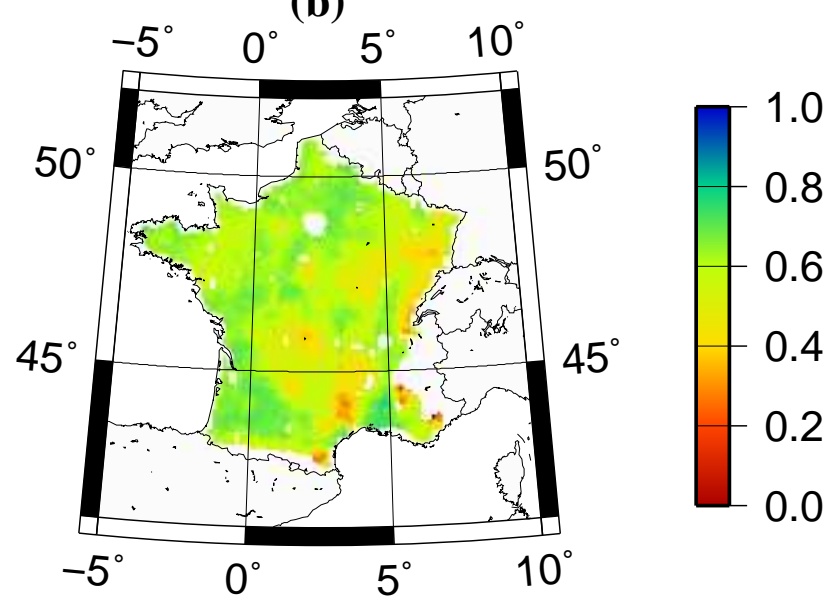

Fig. 1. Maps of (a) absolute correlation and (b) anomaly correlation between (near-real time) SIM $w_{1}$ and ASCAT SDS from January 2007 to May 2010.

near-surface soil moisture is checked in Sect. 3.1. Then the results of assimilating the ASCAT data are compared against the SMOSMANIA in situ data in Sect. 3.2, and against the delayed cut-off SIM model output in Sect. 3.3.

\subsection{Preliminary comparison of ASCAT and SIM near- surface soil moisture}

Figure 1 shows maps of the correlation $\left(r_{\mathrm{abs}}\right)$ and anomaly correlation $\left(r_{\mathrm{anm}}\right.$; with anomalies defined as the difference from the 31 day moving average) between the SIM_NRT $w_{1}$ and ASCAT SDS time series at each grid cell. Both maps show a strong association between the two soil moisture estimates, with consistently very high correlations across nearly all of the SIM domain. For $r_{\mathrm{abs}}$, the mean value across France was 0.68 , and $81 \%$ of the grid cells had a value greater than 0.60 , while for $r_{\mathrm{anm}}$, the mean was 0.62 , and $68 \%$ of the grid cells had a value greater than 0.60 . Both maps show similar spatial patterns, in terms of the regions of relatively high
Table 2. Absolute $\left(r_{\text {abs }}\right)$ and anomaly $\left(r_{\text {anm }}\right)$ correlations between the in situ observations from SMOSMANIA, and $w_{1}$ from each of SIM_NRT, SIM_ASCAT, and SIM_DEL, from May 2007 to April 2010. All correlations are significant at $1 \%$.

\begin{tabular}{|c|c|c|c|c|c|c|}
\hline & \multicolumn{2}{|c|}{ SIM_NRT } & \multicolumn{2}{|c|}{ SIM_ASCAT } & \multicolumn{2}{|c|}{ SIM_DEL } \\
\hline & $r_{\mathrm{abs}}$ & $r_{\mathrm{anm}}$ & $r_{\mathrm{abs}}$ & $r_{\text {anm }}$ & $r_{\mathrm{abs}}$ & $r_{\text {anm }}$ \\
\hline SBR & 0.77 & 0.65 & 0.78 & 0.65 & 0.80 & 0.68 \\
\hline URG & 0.64 & 0.66 & 0.67 & 0.67 & 0.71 & 0.69 \\
\hline CRD & 0.70 & 0.56 & 0.73 & 0.57 & 0.72 & 0.57 \\
\hline PRG & 0.68 & 0.46 & 0.70 & 0.47 & 0.71 & 0.47 \\
\hline $\mathrm{CDM}$ & 0.76 & 0.55 & 0.72 & 0.54 & 0.71 & 0.54 \\
\hline LHS & 0.65 & 0.45 & 0.65 & 0.45 & 0.71 & 0.47 \\
\hline SVN & 0.63 & 0.53 & 0.64 & 0.53 & 0.68 & 0.52 \\
\hline MNT & 0.55 & 0.52 & 0.56 & 0.52 & 0.64 & 0.54 \\
\hline SFL & 0.67 & 0.45 & 0.67 & 0.46 & 0.72 & 0.48 \\
\hline MTM & 0.50 & 0.41 & 0.55 & 0.46 & 0.60 & 0.47 \\
\hline LZC & 0.71 & 0.62 & 0.72 & 0.62 & 0.74 & 0.62 \\
\hline NBN & 0.67 & 0.49 & 0.67 & 0.49 & 0.66 & 0.48 \\
\hline
\end{tabular}

and low values, including several locations with low correlations $(<0.3)$ in regions of mountainous terrain. In each case these were adjacent to locations where the ASCAT data were screened out due to complex terrain and/or vegetation cover, suggesting that the low correlations were associated with ASCAT errors, and the parameters used to screen-out the ASCAT data were insufficiently rigorous.

Since the SIM and ASCAT soil moisture are derived using totally independent methods, this strong temporal agreement between them is extremely encouraging. It both confirms the viability of assimilating the ASCAT data into SIM, while also confirming that both SIM and ASCAT are accurately estimating near-surface soil moisture dynamics over nearly all of France. The SIM_NRT $w_{1}$ was used in the above comparison, however similar results were obtained using the SIM DEL $w_{1}$ also. Using the latter die not result in visible differences in the correlation maps, while the mean correlations between ASCAT and SIM were very slightly increased (by 0.01 in each case).

\subsection{Evaluation against SMOSMANIA in situ observations}

Consistent with previous studies comparing ASCAT soil moisture to in situ observations (Albergel et al., 2009; Brocca et al., 2010a), there is a strong agreement between the ASCAT SDS data and the SMOSMANIA in situ observations. Prior to the assimilation, the ASCAT data had higher anomaly correlations to the in situ data than SIM_NRT did for 10 of the 12 SMOSMANIA stations, giving mean anomaly correlations across the 12 stations of 0.62 for ASCAT and 0.57 for SIM_NRT (based on the SIM_NRT $w_{1}$ sampled at the same times as the ASCAT observations). However, the absolute correlations to the SMOSMANIA 

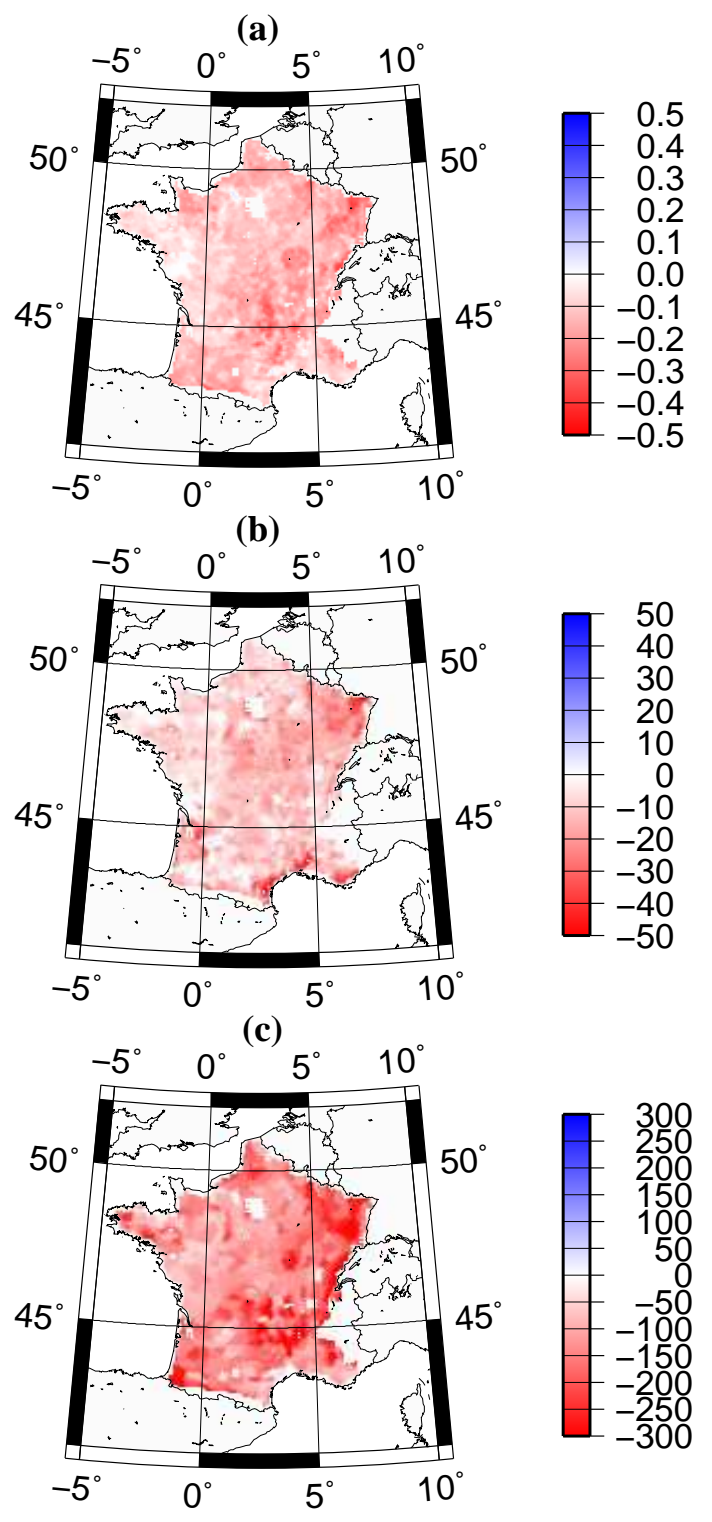

Fig. 2. Net bias from May 2007 to April 2010 between SIM_NRT and SIM_DEL for (a) $w_{1}(\mathrm{~mm}),(\mathbf{b}) w_{2}(\mathrm{~mm})$, and (c) precipitation forcing $\left(\mathrm{mm} \mathrm{yr}^{-1}\right)$.

data were more evenly spread, and ASCAT had a slightly lower mean correlation (0.70) than SIM_NRT (0.71).

Table 2 shows the correlation statistics comparing the near-surface soil moisture from each of the SIM experiments to the SMOSMANIA in situ data. While assimilating the ASCAT data did improve the SIM_NRT correlations at most of the sites (only CDM was degraded), these improvements were very small $(<0.01$ in some instances $)$, and generated only a very small improvement in the mean $r_{\mathrm{abs}}\left(r_{\mathrm{anm}}\right)$ to 0.67 (0.54) for SIM_ASCAT, compared to $0.66(0.53)$ for SIM_NRT. While the consistency of the higher correlations for SIM_ASCAT is encouraging, these very small improvements are far from statistically (or practically) significant.
The limited impact of the assimilation against the SMOSMANIA data is likely a consequence of the comparison having been based on near-surface soil moisture. The ISBA $w_{1}$ variable is strongly determined by the atmospheric forcing, and is less affected by the analyses updates than $w_{2}$ (as will be demonstrated in Sect. 3.3.2).

Additionally, it is interesting to note that in Table 2, SIM_DEL consistently had higher correlations with the SMOSMANIA time series than SIM_NRT did, giving higher mean $r_{\mathrm{abs}}\left(r_{\mathrm{anm}}\right)$ for SIM_DEL of $0.70(0.59)$. This supports the assumption in the following section that the SIM_DEL soil moisture is more accurate than that of SIM_NRT, while also indicating that the SMOSMANIA observations are sufficiently accurate to detect the difference in accuracy between SIM_NRT and SIM_DEL.

\subsection{Evaluation against the delayed cut-off SIM forecasts}

\subsubsection{SIM NRT and SIM_DEL}

Before comparing the ASCAT assimilation results to SIM_DEL, SIM_NRT and SIM_DEL are first compared to each other to establish the impact of the NRT SAFRAN errors on the ISBA model output. Since there is a strong seasonal cycle in the impact of the assimilation, all statistics from this point forward are calculated from three complete years of data, from May 2007 to April 2010 (using the full 3.5 year period does not change the relative performance of each simulation).

The temporal behaviour of the SIM_NRT and SIM_DEL soil moisture forecasts was very similar. For $w_{1}, r_{\text {abs }}$ averaged across the domain for the three years from May 2007 was 0.95 , and $98 \%$ of the grid cells had a value above 0.90 . Likewise $r_{\text {anm }}$ had a mean of 0.95 , with $96 \%$ of the grid cells above 0.90 . For $w_{2}$, the mean $r_{\text {abs }}$ was 0.95 , with $88 \%$ of the grid cells above 0.90, while the mean $r_{\text {anm }}$ was 0.94 , with $87 \%$ of the grid cells above 0.90 . The lower mean correlations for $w_{2}$ were caused by lower values in mountainous regions, where the variable terrain increases the spatial variability in the near-surface atmosphere, emphasising the impact of the enhanced observation density in the DEL SAFRAN analysis.

It is extremely unlikely, and also unnecessary, for the assimilation to correct the small errors in the temporal behaviour between SIM_NRT and SIM_DEL. However, while their temporal variability was similar, there were substantial differences between the absolute soil moisture simulated by SIM_DEL and SIM_NRT, particularly for $w_{2}$. For $w_{1}$, the spatial mean of the temporal Root Mean Square Error (RMSE) between SIM_NRT and SIM_DEL was $0.028 \mathrm{~m}^{3} \mathrm{~m}^{-3}(-0.28 \mathrm{~mm}$, compared to a spatial mean temporal standard deviation of $0.8 \mathrm{~mm}$ ), while for $w_{2}$ the mean RMSE was $0.010 \mathrm{~m}^{3} \mathrm{~m}^{-3}(16.6 \mathrm{~mm}$, compared to a mean temporal standard deviation of $47.0 \mathrm{~mm}$ ). The main contributor to these large RMSE values was a substantial dry 

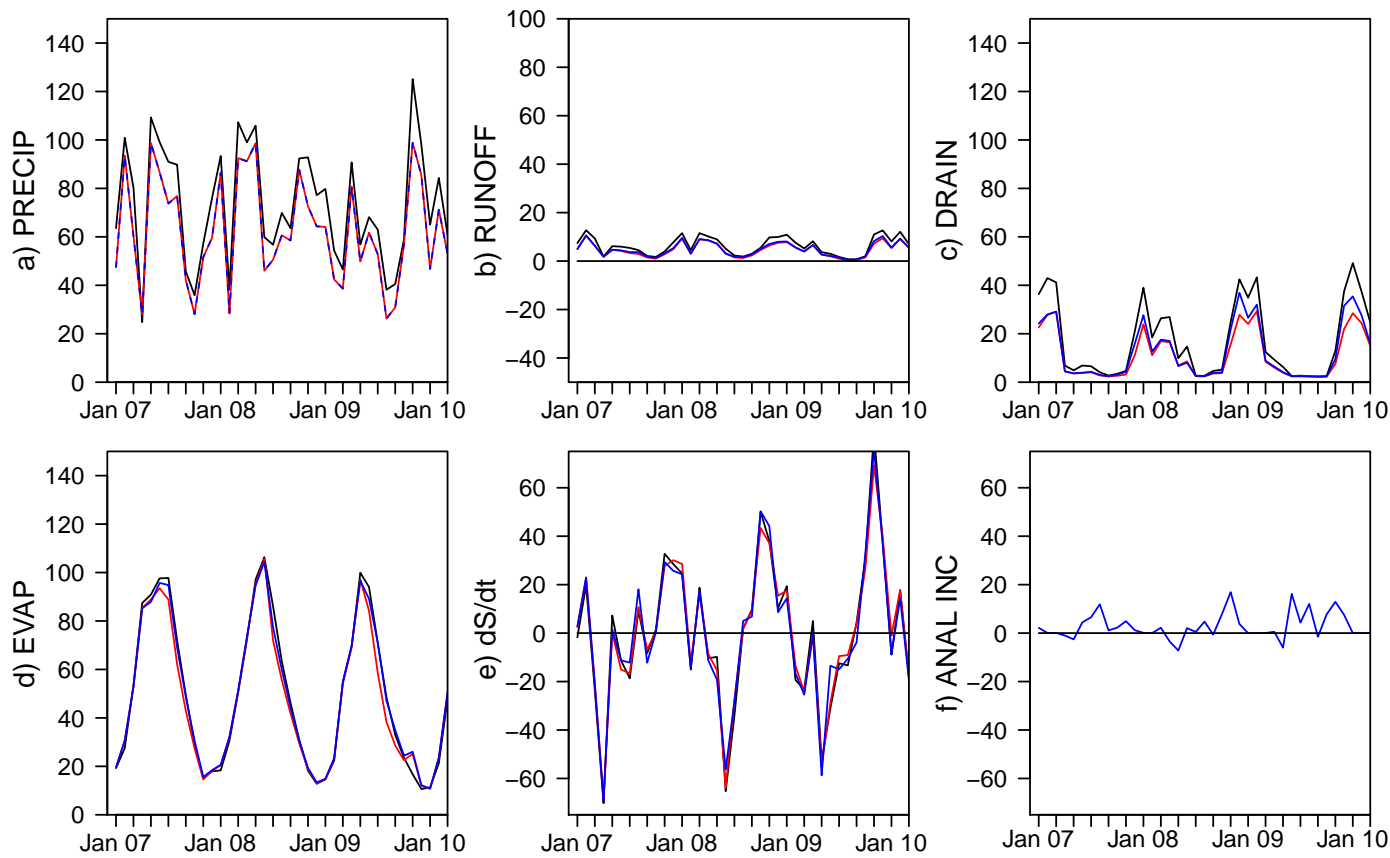

Fig. 3. Monthly water balance in $m m m^{-1}$ for SIM_DEL (black), SIM_NRT (red), and SIM_ASCAT (blue). Each panel shows (a) precipitation, (b) runoff, (c) drainage, (d) evapotranspiration, (e) change in surface moisture storage (all soil layers, liquid plus solid), and (f) the analysis increments (for SIM_ASCAT).

bias in the SIM_NRT soil moisture. Figure 2 shows maps of the mean difference in $w_{1}$ and $w_{2}$ between the two simulations, demonstrating that SIM_NRT was on average drier than SIM_DEL across nearly all of France. Relative to SIM_DEL, the mean temporal bias in the SIM_NRT $w_{1}$ was $-0.011 \mathrm{~m}^{3} \mathrm{~m}^{-3}$ (or $0.11 \mathrm{~mm}$ ), while for $w_{2}$ the mean bias was $-0.009 \mathrm{~m}^{3} \mathrm{~m}^{-3}$ (or $-12.1 \mathrm{~mm}$ ).

This dry bias in the NRT soil moisture was caused by a dry bias in the NRT SAFRAN precipitation analysis. Figure 2c shows that the NRT precipitation is also biased low (compared to the DEL precipitation) across nearly all of France, with the bias reaching $200 \mathrm{~mm} \mathrm{yr}^{-1}$ at some locations. Additionally, there is a reasonably strong spatial correspondence between the precipitation and soil moisture biases in Fig. 2, including the same isolated regions of positive bias. The precipitation bias is thought to be due to the underestimation of precipitation by automatic weather station rain gauges (Canellas, 2005), and the tendency for the sparser observation network to detect fewer rain events.

Figure 3 shows time series of the monthly mean surface water balance terms, from SIM_DEL and SIM_NRT, while Fig. 4 shows time series of the monthly mean difference between the SIM_DEL and SIM_NRT forecasts. Precipitation is generated by SAFRAN, while the remaining surface water balance terms are generated by ISBA. Figure $4 \mathrm{a}$ shows that the dry SIM_NRT precipitation bias occurred persistently throughout the year, with a tendency for larger biases around winter, generating a large mean monthly bias of $-10.0 \mathrm{~mm} \mathrm{month}^{-1}$ for the three years from May 2007. Fig- ure 5 shows the temporal evolution of the spatially averaged $w_{2}$, demonstrating that the precipitation bias induced a $w_{2}$ bias of -10 to $-20 \mathrm{~mm}$ throughout the year.

In ISBA, drainage and runoff are triggered when soil moisture exceeds saturation, so that both reach their maxima during winter, coinciding with the soil moisture maxima. In response to the dry biased soil moisture in SIM_NRT both of these terms are biased low, with the greatest biases occurring in winter. Since the drainage itself is much larger than the runoff, the mean monthly drainage SIM_NRT bias $\left(-5.8 \mathrm{~mm} \mathrm{month}^{-1}\right)$ was much larger than the mean monthly runoff bias $\left(-1.6 \mathrm{~mm} \mathrm{month}^{-1}\right)$. In fact the drainage bias accounted for over half of the dry SIM_NRT precipitation bias.

Evapotranspiration has the opposite seasonal cycle with maxima in summer, coinciding with maximum insolation. In each year the SIM_NRT evapotranspiration was biased low in late summer, when surface drying causes transpiration to become moisture limited. This negative evaporation bias during summer (larger than $-5 \mathrm{~mm} \mathrm{month}^{-1}$ ) was offset by a small positive bias during the wetter months (of approximately $1 \mathrm{~mm}$ month $^{-1}$ ), generating a mean bias of just $-2.4 \mathrm{~mm} \mathrm{month}^{-1}$. This is relatively small given that evapotranspiration is the largest water balance term after precipitation.

The seasonal behaviour of the monthly change in surface moisture storage is less consistent than the other terms, with periods of positive and negative errors offsetting each other to give a very small net change over multi-annual time periods. Since the applied precipitation bias is almost completely 

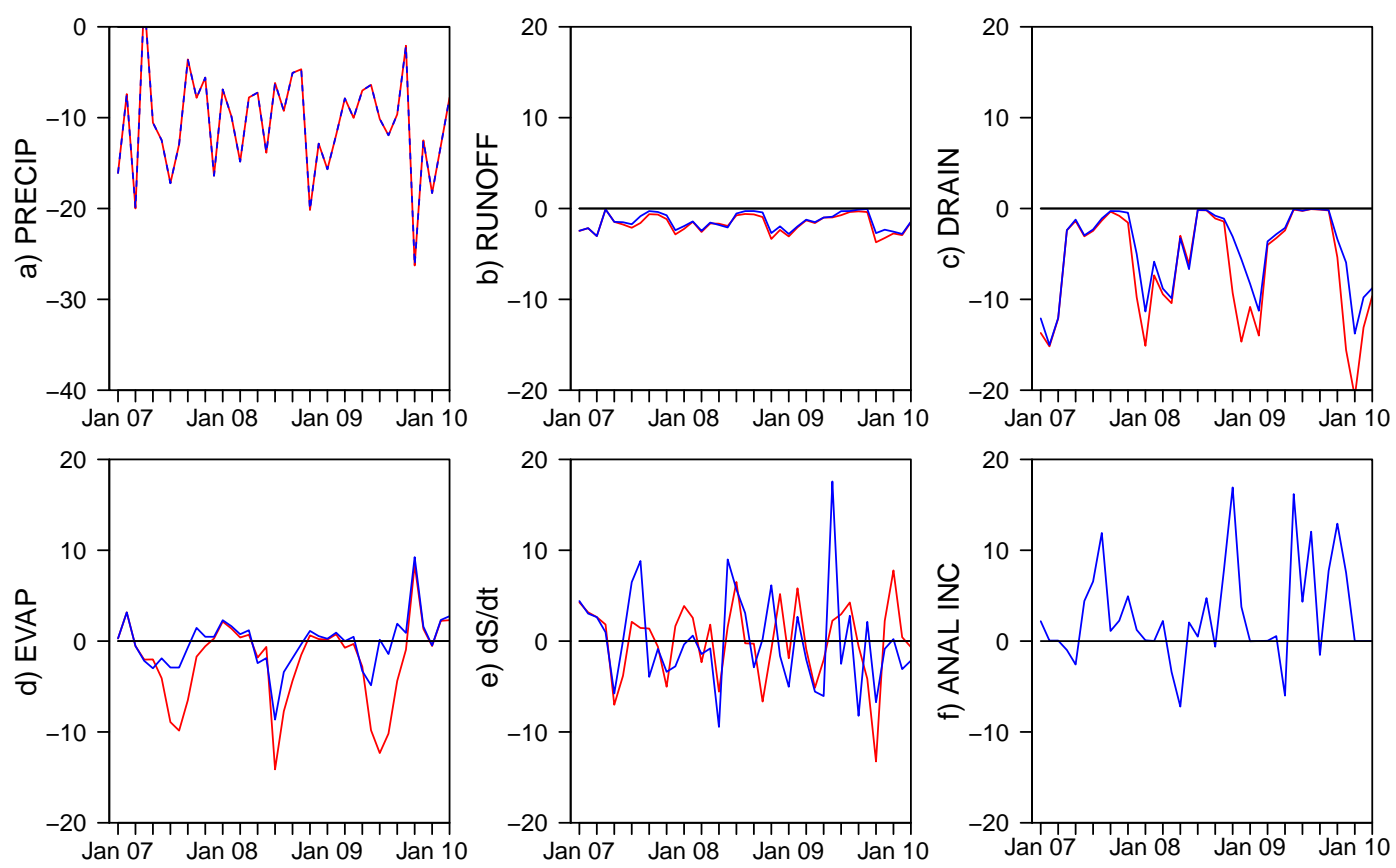

Fig. 4. Mean error relative to SIM_DEL in $m m m^{-1}$ of the monthly water balance terms for SIM_NRT (red) and SIM_ASCAT (blue). Each panel shows (a) precipitation, (b) runoff, (c) drainage, (d) evapotranspiration, (e) change in surface moisture storage (all soil layers, liquid plus solid), and (f) the analysis increments (for SIM_ASCAT).

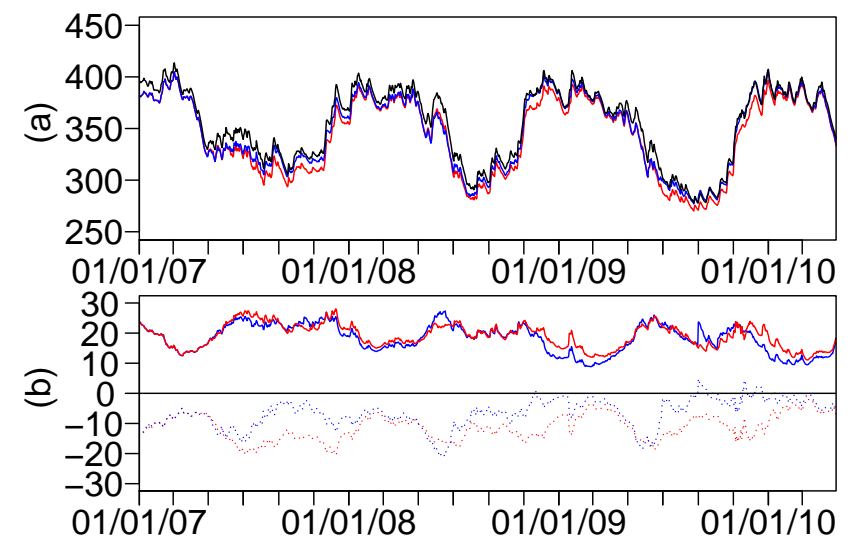

Fig. 5. Time series of the spatial mean (a) $w_{2}$, and (b) $w_{2}$ bias (dotted lines) and $w_{2}$ RMSE (solid lines) relative to SIM_DEL. SIM_DEL is plotted in black, SIM_NRT in red, and SIM_ASCAT in blue, and both plots are in $\mathrm{mm}$.

balanced by the resultant biases (over annual time scales) in drainage, runoff, and evapotranspiration, the mean bias in the change in moisture storage is just $-0.1 \mathrm{~mm} \mathrm{month}^{-1}$. The very small bias in the SIM_NRT $\Delta S / \Delta t$ demonstrates how the dry-biased NRT precipitation caused ISBA to shift to an alternative biased climate (rather than continue to dry down in response to the underestimated precipitation).

Finally, to demonstrate the practical relevance of these errors, the drainage and runoff forecasts from SIM_NRT and

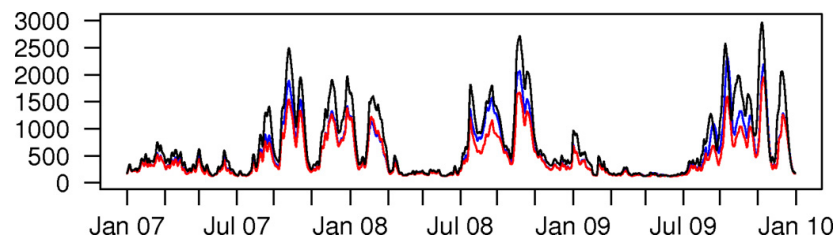

Fig. 6. Discharge $\left(\mathrm{m}^{3}\right.$ day $\left.^{-1}\right)$ from SIM_DEL (black), SIM_NRT (red), SIM_ASCAT (blue), for the River Seine at Poses.

SIM_DEL have been routed through the surface river network with the MODCOU model, and an example hydrograph is shown in Fig. 6. SIM_NRT simulated the timing of flood events from SIM_DEL very well, while consistently underestimating the magnitude of the peak flows, resulting in a discharge ratio relative to SIM_DEL (forecast discharge/SIM_DEL discharge) of 0.76, while the NashSutcliffe Efficiency (E) relative to SIM_DEL was 0.74. These statistics are representative of the streamflow forecasts across France, and the mean discharge ratio relative to SIM_DEL across the 907 stations modeled by MODCOU was 0.68 , while the mean Nash-Sutcliffe efficiency was 0.62 .

When considered in the context of the SIM_DEL model, it is apparent that the SIM_NRT model used in this study was biased, and yet a bias-blind assimilation has been used here, with the ASCAT observations rescaled to match the biased SIM_NRT (as is standard practice in soil moisture assimilation). Since Sects. 3.1 and 3.2 showed that the ASCAT 


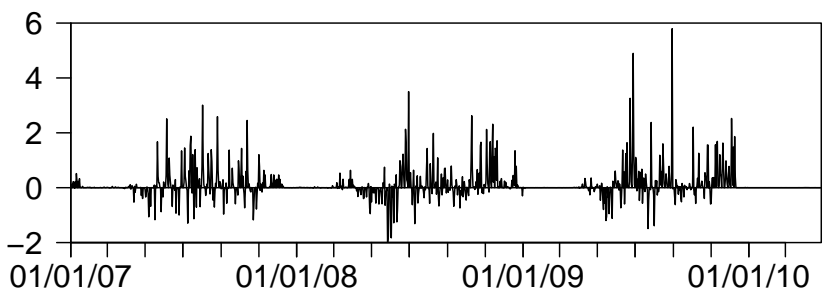

Fig. 7. Time series of the spatial mean volume of moisture $\left(\mathrm{mm} \mathrm{day}^{-1}\right)$ added to the surface $\left(w_{1}\right.$ plus $\left.w_{2}\right)$ through assimilation of the ASCAT SDS.

observations are reasonably accurate, we will proceed to compare SIM_ASCAT against SIM_DEL in the hope that, even after being rescaled to match the mean SIM_NRT (over the full data record), the ASCAT observations have still detected the occurrence of underestimated or absent precipitation events. While in a nonlinear model, a bias blind assimilation would not be expected to affect a bias, land surface models are highly nonlinear, and it is not uncommon to see change in the mean soil moisture from assimilation of unbiased (relative to the model) observations (e.g. Muñoz Sabater et al., 2007).

\subsubsection{SIM_ASCAT and SIM_DEL}

Despite the assimilated ASCAT observations being unbiased relative to the model, the assimilation had a strong tendency to add moisture to $w_{2}$, with a mean net increment of $0.1 \mathrm{~mm} \mathrm{day}^{-1}$. Figure 7 shows time series of the average volume of moisture added across France each day. Very little moisture was added or subtracted during the winter months, due to the widespread occurrence of frozen surface conditions, as well as the reduced vertical soil moisture coupling in ISBA during winter.

Spatially, the assimilation added net moisture at nearly all model grid cells, with only a handful of isolated occurrences of net moisture removal. These locations do not correspond to the locations of positive precipitation and soil moisture biases in Fig. 2. Nor do the regions of strongest moisture addition correspond to the regions of strongest precipitation and soil moisture biases, although this could be due to any number of confounding factors.

Figure 8 shows maps of the soil moisture bias between SIM_ASCAT and SIM_DEL, while Fig. 9 shows maps of the reduction in the RMSE, relative to SIM_DEL, generated by assimilating the ASCAT soil moisture. Comparing Fig. 8 to Fig. 2 shows that the positive soil moisture increments added by SIM_ASCAT reduced the negative SIM_NRT soil moisture biases. For $w_{1}$, there were very small reductions in the net bias at most grid cells (at $78 \%$ of cells across the domain, and at $94 \%$ of the cells which have ASCAT observations), with slightly larger reductions of approximately $0.02 \mathrm{~mm}$ in the north of France. Overall, the mean bias for the three years from May 2007 was slightly reduced to $-0.09 \mathrm{~mm}$ (from
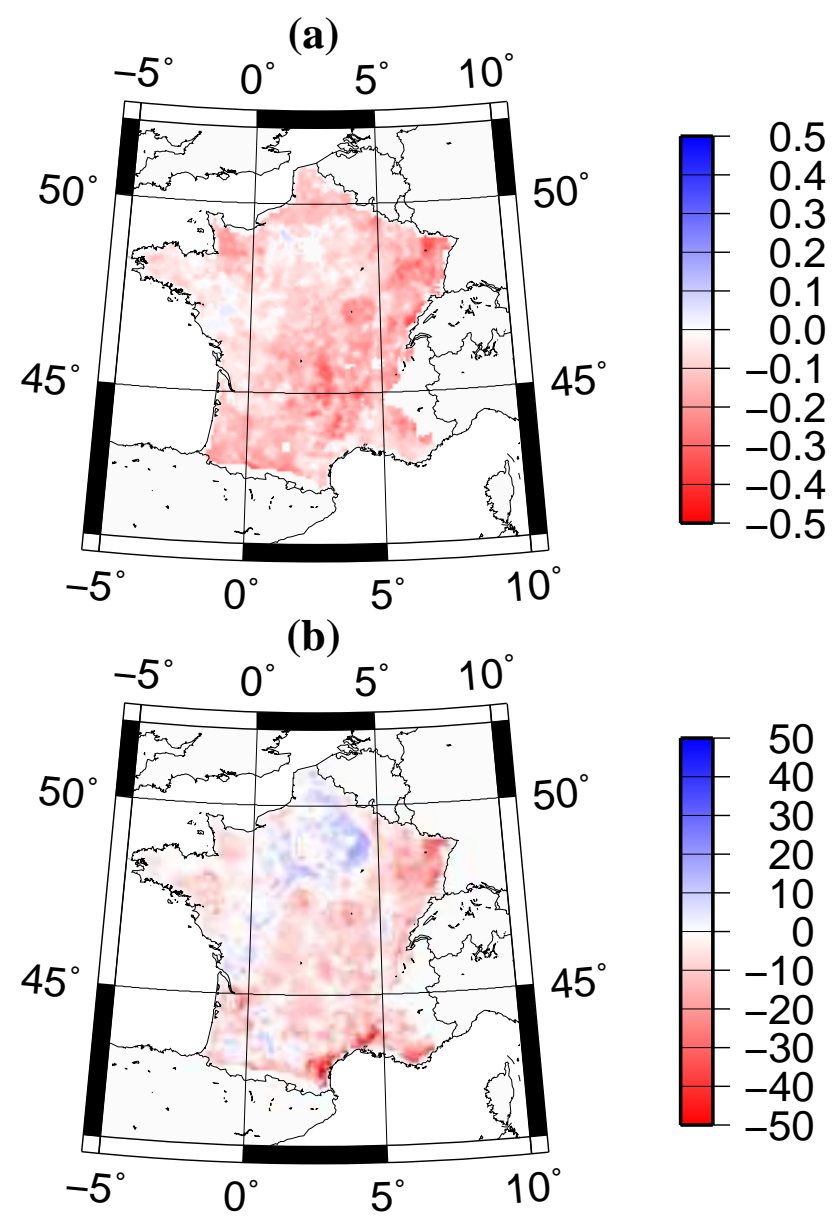

Fig. 8. Net bias from May 2007 to April 2010 (in mm) between SIM_ASCAT and SIM_DEL for (a) $w_{1}$, and (b) $w_{2}$.

$-0.11 \mathrm{~mm}$ for SIM_NRT). This reduced the RMSE also: at $59 \%$ of the grid cells (and at $71 \%$ of cells with ASCAT data), although the reductions were extremely small, and the mean RMSE was unchanged from $0.28 \mathrm{~mm}$ for both SIM_NRT and SIM_ASCAT.

Since $w_{2}$ has a much longer memory, the impact of the assimilation on $w_{2}$ was much greater. While the magnitude of the negative $w_{2}$ bias was reduced across most of France, a small positive bias was introduced in the northeast and southwest in Fig. 8 (in the northeast this caused a relatively large increase in the RMSE in Fig. 9). Overall, the assimilation reduced the mean bias for $w_{2}$ to $-5.6 \mathrm{~mm}$ (from $-12.1 \mathrm{~mm}$ ), while the absolute bias was reduced at $73 \%$ of the grid cells (and at $89 \%$ of the cells with ASCAT data). Consequently, the $w_{2}$ RMSE was reduced at $57 \%$ of the model grid cells (and at $69 \%$ of cells with ASCAT data), decreasing the mean $w_{2}$ RMSE to $15.8 \mathrm{~mm}$ (from $16.6 \mathrm{~mm}$ for SIM_NRT).

Temporally, the assimilation reduced the magnitude of the negative $w_{2}$ biases in the time series in Fig. 5, with the greatest reductions (of around $10 \mathrm{~mm}$ ) occurring through the summer, and persisting into early winter, before being lost in late 
(a)
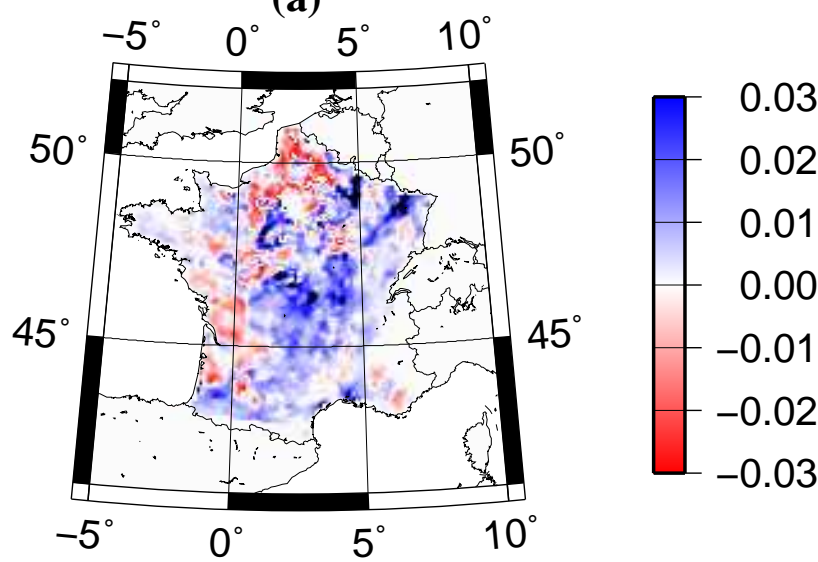

(b)
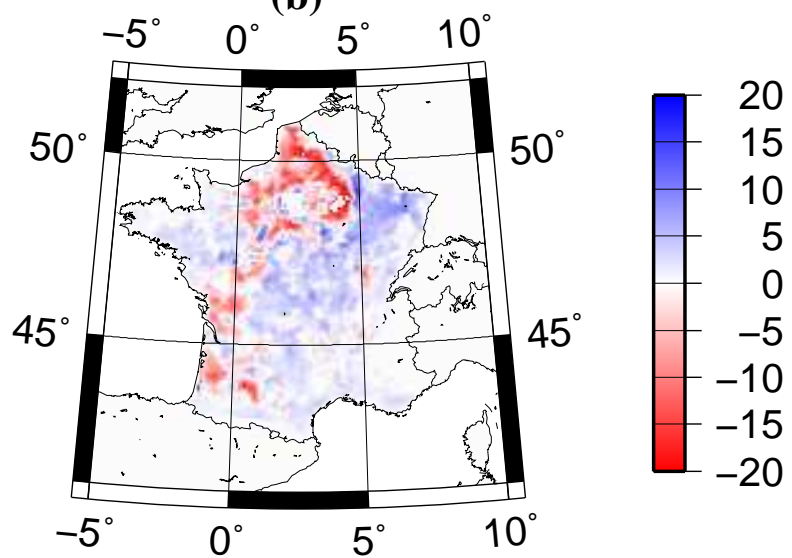

Fig. 9. Reduction in the RMSE relative to SIM_DEL (in $\mathrm{mm}$ ) from the assimilation of ASCAT, for (a) $w_{1}$ and (b) $w_{2}$, from May 2007 to April 2010.

winter. The assimilation also reduced the spatial RMSE between the simulated $w_{2}$ and SIM_DEL (by up to $5 \mathrm{~mm}$ ) on most days.

While the reduced soil moisture bias is consistent with the assimilation having correctly updated the model in response to the underestimated NRT SAFRAN precipitation, an investigation of the assimilation system and model physics indicated that there are additional reasons for the net addition of moisture. The Kalman gain for updating $w_{2}\left(\mathbf{K}_{2}\right)$ had a strong tendency to be higher when the observation departure was more positive. For example, averaged across the whole experiment, the mean $\mathbf{K}_{2}$ for positive observation departures was $0.063 \mathrm{~m}^{3} \mathrm{~m}^{-3}$, while for negative observation departures it was $0.030 \mathrm{~m}^{3} \mathrm{~m}^{-3}$.

The main cause of the asymmetric behaviour in $\mathbf{K}_{2}$ was the observation operator, which was a $24 \mathrm{~h}$ integration of the forecast model (SIM), followed by conversion to the observation equivalent variable $\left(w_{1}\right)$. That is, for $y^{o}=w_{1}$ and $\boldsymbol{x}=$ $\left[w_{1}, w_{2}\right]^{T}, \boldsymbol{H}=\left[\delta w_{1}(t+24) / \delta w_{1}(t), \delta w_{1}(t+24) / \delta w_{2}(t)\right]^{T}$. During precipitation events, $\boldsymbol{H}_{2}=\delta w_{1}(t+24) / \delta w_{2}(t)$ is re- duced, since the signal of $w_{2}$ in $w_{1}$ is overwhelmed by the precipitation. As a result, $\mathcal{H}_{2}$ and consequently $\mathbf{K}_{2}$ tends to be smaller when the model forecast $w_{1}$ is wetter. The observation error variances used in $\mathbf{R}$, which were temporally variable estimates provided with the ASCAT data, had an additional (although lesser) influence on $\mathbf{K}_{2}$. Scatterplots of the observation error variances at individual locations (not shown) show that the error variances generally decrease as the ASCAT observations become wetter (within the range of the ASCAT data used here), resulting in larger $\mathbf{K}_{2}$ for wetter $y^{o}$. In combination these two factors (smaller $\mathbf{K}_{2}$ for wetter $w_{1}$, and larger $\mathbf{K}_{2}$ for wetter $y^{o}$ ) produced a tendency for larger $\mathbf{K}_{2}$ when the observation departure $\left(y^{o}-w_{1}\right)$ was more positive, giving the assimilation a bias towards adding positive soil moisture analysis increments.

Several adjustments to the EKF could help to address this bias in the SEKF. The monotonic relationship between the ASCAT observations and their error variances would be most easily addressed by reverting to a constant $\mathbf{R}$, as is more often used in soil moisture assimilation. For $\mathcal{H}_{2}$, since $w_{1}$ is not influenced by $w_{2}$ during precipitation, this tendency to decrease is physically sensible. However, the model forecast error variances should also be larger during precipitation, to reflect the uncertainty in the SAFRAN precipitation analysis (recall from Sect. 3.3.1 that the timing of precipitation events is reasonable, while the volume is less certain). This cannot be easily accounted for in the simplified EKF, and a more sophisticated assimilation strategy, such as an ensemble Kalman filter could better address this. Alternatively, adopting an additive forecast error term $(\mathbf{Q})$ parameterised to depend on the precipitation forcing in the (nonsimplified) EKF could help provide a more symmetric relationship between $\mathbf{K}_{2}$ and forecast $w_{1}$. Work is under way to incorporate a rainfall-dependent $\mathbf{Q}$ into the EKF for use in NWP (Mahfouf, 2010) that could be adapted for SIM.

Even though the ASCAT assimilation is not thought to have accurately responded to the NRT SAFRAN errors, the impact of the assimilation on the surface moisture fluxes is examined below to demonstrate how the model responded to the reduced $w_{2}$ biases induced by the assimilation. The monthly mean water balance terms for SIM_ASCAT are included in Figs. 3 and 4. As discussed previously the analysis increments tended to be positive, giving a mean monthly increment of $+4.2 \mathrm{~mm} \mathrm{month}^{-1}$. The wetter soil moisture in SIM_ASCAT then led to reductions in the magnitude of the negative biases in the resultant moisture flux forecasts, to $-4.1 \mathrm{~mm} \mathrm{month}^{-1}$ for drainage (a reduction of $1.7 \mathrm{~mm}$ ), $-1.4 \mathrm{~mm} \mathrm{month}^{-1}$ for runoff (a reduction of $0.2 \mathrm{~mm}$ ), and $-0.2 \mathrm{~mm} \mathrm{month}^{-1}$ for evaporation (a reduction of $2.2 \mathrm{~mm}$ ). Since the addition of soil moisture by the assimilation was balanced by reductions in the drainage, runoff, and evapotranspiration biases, there was no net change in the bias (over annual time periods) in the monthly change in moisture storage of $0.1 \mathrm{~mm} \mathrm{month}^{-1}$. Hence in Fig. 5, the SIM_ASCAT and SIM_NRT $w_{2}$ time series converge during winter when 
the assimilation is less active, due largely to the enhanced SIM_ASCAT drainage forecasts.

Note that the assimilation had the greatest (absolute) impact on the drainage forecasts, and just over $40 \%$ of the soil moisture increments were subsequently lost from the surface as additional drainage forecasts. This demonstrates the potential for improved soil moisture to have a significant impact on hydrological forecasting applications. A similar result was obtained by van den Hurk et al. (2008) from a soil moisture analysis in the ECMWF IFS model, in that at many (nonMediterranean) locations the majority of the analysis increments added to the soil were translated into drainage/runoff, rather than changes in soil moisture storage or evapotranspiration.

As expected, the increased drainage and runoff forecast from SIM_ASCAT increased the forecast peak streamflows in Fig. 6, increasing the discharge ratio relative to SIM_DEL to 0.78 (from 0.76 for SIM_NRT), and increasing the NashSutcliffe Efficiency to 0.77 (from 0.74 for SIM_NRT). Similar results were obtained across the majority of the gauging stations modeled by MODCOU. SIM_ASCAT reduced the absolute error in the discharge ratio (i.e. difference from unity) at $88 \%$ of the gauging stations, increasing the mean discharge ratio relative to SIM_DEL to 0.76 (from 0.68 for SIM_NRT). Additionally, the Nash-Sutcliffe Efficiency, which is more sensitive to the accuracy of the timing (and magnitude) of the peak flows, increased at $82 \%$ of the stations, increasing the mean to 0.68 (from 0.62 for SIM_NRT).

\section{Summary and conclusions}

This study sought to investigate whether the assimilation of ASCAT surface degree of saturation data might benefit Météo-France's SAFRAN-ISBA-MODCOU (SIM) hydrological model. SIM is run operationally at Météo-France in near-real time to provide output for use in ensemble streamflow prediction and flood forecasting systems. The benefit of the ASCAT data was tested by assimilating it from January 2007-May 2010 into a research copy of the near-real time operational SIM model with a simplified EKF.

The ASCAT surface degree of saturation data were shown to be accurate, with good absolute and anomaly correlations with in situ data from the SMOSMANIA monitoring network, and also with (completely independent) SIM nearsurface soil moisture forecasts across nearly all of the France. Assimilating the ASCAT observations into the near-real time SIM model generated very small improvements in the model near-surface soil moisture, compared to the SMOSMANIA in situ observations, although these improvements were not sufficient to be practically or statistically significant.

The potential for the ASCAT assimilation to correct for errors in the near-real time SIM forcing was then tested by comparison against the more accurate delayed cut-off SIM stream. However, comparing the SIM_NRT and SIM_DEL model output revealed that the most significant difference between them is a substantial dry bias in the near-real time precipitation. This caused a dry bias in the SIM_NRT soil moisture and resultant surface moisture flux forecasts, including streamflow (of most importance to operational users of SIM).

This dry bias in the near-real time SIM model (revealed by comparison to the delayed cut-off stream) represents a bias in the forecast model that has been used in the ASCAT assimilation experiments. A bias in the forecast model (or assimilated observations) invalidates key assumptions of (biasblind) data assimilation, leading to sub-optimal filter performance (Dee, 2005). However, since the true soil moisture climatology is unknown at large spatial scales (Reichle et al., 2004), it is common in soil moisture assimilation to at least ensure that the model and observations are unbiased relative to each other. In theory, eliminating the bias between the forecast model and the observations will allow the assimilation to correct for other errors in the model, as was possibly indicated by the very small increase in correlations against the in situ SMOSMANIA data obtained here.

While a bias-blind assimilation of the ASCAT data was not expected to address the SIM_NRT forecast model biases, it did in fact reduce the model bias. However, this was likely due to a bias in the assimilation system, rather than the assimilation having accurately responded to the NRT precipitation errors, and so this is not regarded as a successful outcome for these experiments.

The obvious alternative to the bias-blind assimilation strategy used here is to implement a bias-aware assimilation (e.g. De Lannoy et al., 2007). However, the success of a bias aware assimilation is strongly dependent on the method used to estimate the forecast model biases, to the extent that Dee (2005) recommends foregoing a bias-aware assimilation unless the biases can be confidently estimated. For the operational SIM model, a model for predicting the biases could potentially be based on the SIM_DEL model (which was set aside for evaluation in this study). However, when the SEKF added moisture to the surface in this experiment, this resulted in enhanced surface flux forecasts (particularly for drainage which accounted for $40 \%$ of the analysis increments). As a result the model had a strong tendency to dry back to its original biased climatology, as dictated by the precipitation forcing. Consequently, even with a perfectly functioning biasaware assimilation, in instances when vegetation, frozen conditions, or some other cause prevents observations from being assimilated, the model will quickly return to its preferred (biased) climatology.

This highlights that in general it is better to address the cause of a model bias, rather than rely on an assimilation to correct it. Accordingly, work is under way to address the dry bias in the near-real time SAFRAN precipitation analysis. This bias is not consistent in time, and is difficult to treat with a bias-correction scheme. Consequently, the possibility of replacing the current SAFRAN precipitation analysis with one based on the CANARI OI scheme (Taillefer, 2002) 
is currently being investigated. However, even with the precipitation bias accounted for, other errors will persist in the model soil moisture (e.g. Berg and Famiglietti, 2003), and ultimately SIM will likely benefit from a combination of a soil moisture analysis scheme and improved precipitation forcing. For example (while precipitation bias is not explicitly addressed) Liu et al. (2011) showed that assimilating nearsurface soil moisture and applying a rain-gauge based correction to precipitation forcing generated greater improvements in modeled soil moisture skill than applying either of these techniques separately.

Acknowledgements. The EUMETSAT H-SAF Associated Scientist Program is acknowledged for funding the work presented here.

Edited by: A. Loew

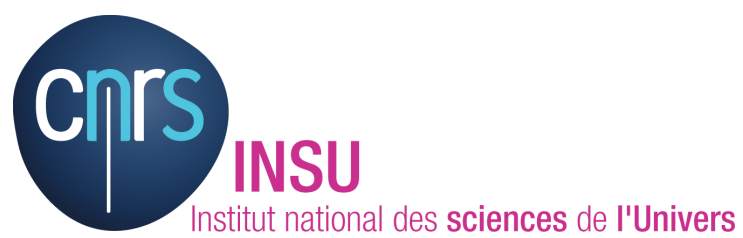

The publication of this article is financed by CNRS-INSU.

\section{References}

Albergel, C., Rüdiger, C., Pellarin, T., Calvet, J.-C., Fritz, N., Froissard, F., Suquia, D., Petitpa, A., Piguet, B., and Martin, E.: From near-surface to root-zone soil moisture using an exponential filter: an assessment of the method based on in-situ observations and model simulations, Hydrol. Earth Syst. Sci., 12, 1323-1337, doi:10.5194/hess-12-1323-2008, 2008.

Albergel, C., Rüdiger, C., Carrer, D., Calvet, J.-C., Fritz, N., Naeimi, V., Bartalis, Z., and Hasenauer, S.: An evaluation of ASCAT surface soil moisture products with in-situ observations in Southwestern France, Hydrol. Earth Syst. Sci., 13, 115-124, doi:10.5194/hess-13-115-2009, 2009.

Balsamo, G., Bouyssel, F., and Noilhan, J.: A simplified bidimensional variational analysis of soil moisture from screenlevel observations in a mesoscale numerical weather-prediction model, Q. J. Roy. Meteorol. Soc., 130, 895-915, 2004.

Balsamo, G., Mahfouf, J.-F., Bélair, S., and Deblonde, G.: A land data assimilation system for soil moisture and temperature: An information content study, J. Hydrometeorology, 8, 1225-1242, 2007.

Berg, A. and Famiglietti, J.: Characterizing regional uncertainty in the initial soil moisture status, Geophys. Res. Lett., 30, 1466, doi:10.1029/2003GL017075, 2003.

Bolten, J., Crow, W., Jackson, T., Zhan, X., and Reynolds, C.: Evaluating the utility of remotely-sensed soil moisture retrievals for operational agricultural drought monitoring, IEEE Journal of Selected Topics in Applied Earth Observations and Remote Sensing, 3, 57-66, 2010.

Boone, A., Calvet, J.-C., and Noilhan, J.: Inclusion of a third soil layer in a land-surface scheme using the force-restore method, J. Appl. Meteorol., 38, 1611-1630, 1999.
Brocca, L., Hasenauer, S., de Rosnay, P., Melone, F., Moramarco, T., Matgen, P., Martínez-Fernández, J., Llorens, P., Latron, J., and Martin, C.: Consistent validation of H-SAF soil moisture satellite and model products against ground measurements for selected sites in Europe, Associated Scientist Activity in the Framework of the Satellite Application Facility on Support to Operational Hydrology and Water Management (H-SAF) Final Report, available at http://hsaf.meteoam.it/documents/reference/ HSAF_AS_09_03_final_report.pdf, 2010a.

Brocca, L., Melone, F., Moramarco, T., Wagner, W., and Hasenauer, S.: ASCAT soil wetness index validation through in situ and modeled soil moisture data in central Italy, Remote Sens. Environ., 114, 2745-2755, 2010b.

Calvet, J.-C., Fritz, N., Froissard, F., Suquia, D., Petitpa, A., and Piguet, B.: In situ soil moisture observations for the CAL/VAL of SMOS: the SMOSMANIA network, 2007 International Geoscience and Remote Sensing Symposium, Proceedings, 2007.

Canellas, C.: Intercomparison de pluviomèmetres, Metéo-France Note de la Direction de la Production, 2005.

Crow, W. and Wood, E.: The assimilation of remotely sensed soil brightness temperature imagery into a land surface model using Ensemble Kalman filtering: a case study based on ESTAR measurements during SGP97, Adv. Water Resour., 26, 137-149, 2003.

Crow, W., Miralles, D., and Cosh, M.: A quasi-global evaluation system for satellite surface soil moisture retrievals, IEEE Transactions on Geoscience and Remote Sensing, 48, 2516-2527, 2009.

Dee, D.: Bias and data assimilation, Q. J. Roy. Meteorol. Soc., 131, 3323-3343, 2005.

De Lannoy, G., Reichle, R., Houser, P., Pauwels, V., and Verhoest, N.: Correcting for forecast bias in soil moisture assimilation with the Ensemble Kalman Filter, Water Resour. Res., 43, W09410, doi:10.1029/2006WR005449, 2007.

de Rosnay, P., Drusch, M., Balsamo, G., Beljaars, A., Isaksen, L., Vasiljevic, D., Albergel, C., and Scipal, K.: Advances in land data assimilation at ECMWF, ECMWF/GLASS Workshop on Land Surface Modelling and Data Assimilation and the Implications for Predictability, 9-12 November 2009, ECMWF, Reading, UK, 2009.

Dharssi, I., Bovis, K. J., Macpherson, B., and Jones, C. P.: Operational assimilation of ASCAT surface soil wetness at the Met Office, Hydrol. Earth Syst. Sci., 15, 2729-2746, doi:10.5194/hess15-2729-2011, 2011.

Draper, C., Mahfouf, J.-F., and Walker, J.: An EKF assimilation of AMSR-E soil moisture into the ISBA land surface scheme, J. Geophys. Res., 114, D20104, doi:10.1029/2008JD011650, 2009.

Draper, C., Mahfouf, J.-F., and Walker, J.: Root-zone soil moisture from the assimilation of screen-level variables and remotely sensed soil moisture, J. Geophys. Res., 116, D02127, doi:10.1029/2010JD013829, 2011.

Drusch, M.: Initializing numerical weather prediction models with satellite-derived surface soil moisture: Data assimilation experiments with ECMWF's Integrated Forecast System and the TMI soil moisture data set, J. Geophys. Res., 112, D03102, doi:10.1029/2006JD007478, 2007.

Entekhabi, D., Njoku, E., Houser, P., Spencer, M., Doiron, T., Kim, Y., Smith, J., Girard, R., Bélair, S., Crow, W., Jackson, T., Kerr, Y., Kimball, J., Koster, R., McDonald, K., O’Neill, P., Pultz, T., 
Running, S., Shi, J., Wood, E., and van Zyl, J.: The hydrosphere state (Hydros) satellite mission: An earth system pathfinder for global mapping of soil moisture and land freeze/thaw, IEEE Transactions on Geoscience and Remote Sensing, 42, 21842195, 2004.

Habets, F., Boone, A., Champeaux, J.-L., Etchevers, P., Franchistéguy, L., Leblois, E., Ledoux, E., Le Moigne, P., Martin, E., Morel, S., Noilhan, J., and QuintanaSeguì, P.: The SAFRAN-ISBA-MODCOU hydrometeorological model applied over France, J. Geophys. Res., 113, D06113, doi:10.1029/2007JD008548, 2008.

Houser, P., Shuttleworth, W., Famiglietti, J., Gupta, H., Syed, K., and Goodrich, D.: Integration of soil moisture remote sensing and hydrologic modeling using data assimilation, Water Resour. Res., 34, 3405-3420, 1998.

Kerr, Y., Waldteufel, P., Wigneron, J., Martinuzzi, J., Font, J., and Berger, M.: Soil moisture retrieval from space: The Soil Moisture and Ocean Salinity (SMOS) mission, IEEE Transactions on Geoscience and Remote Sensing, 39, 1729-1735, 2001.

Ledoux, E., Girard, G., Marsily, G. D., and Deschenes, J.: Unsaturated Flow Hydrologic Modeling: Theory and Practice, chap. Spatially distributed modeling: Conceptual approach, coupling surface water and ground-water, pp. 435-454, NATO ASI Series C, vol. 275, 1989.

Liu, Q., Reichle, R., Bindlish, R., Cosh, M., Crow, W., de Jeu, R., De Lannoy, G., Huffman, G., and Jackson, T.: The contributions of precipitation and soil moisture observations to the skill of soil moisture estimates in a land data assimilation system, J. Hydrometeorology, 12, doi:10.1175/JHM-D-10-05000.1, 2011.

Mahfouf, J.-F.: Amelioration des statistiques des erreurs d'ebauche pour l'analyse de l'etat hydrique des sols, in: Ateliers de Modélisation de l'Atmosphère 2010, Toulouse, 26-28 January 2010, at http://www.cnrm.meteo.fr/ama2010/resumes courts/resume_69.html, last accessed June 2010.

Mahfouf, J.-F., Bergaoui, K., Draper, C., Bouyssel, C., Taillefer, F., and Taseva, L.: A comparison of two off-line soil analysis schemes for assimilation of screen-level observations, J. Geophys. Res., 114, D08105, doi:10.1029/2008JD011077, 2009.

Masson, V., Champeaux, J.-L., Chauvin, F., Meriguet, C., and Lacaze, R.: A global database of land surface parameters at 1-km resolution in meteorological and climate models, J. Climate, 16, 1261-1282, 2003.

Muñoz Sabater, J., Jarlan, L., Calvet, J.-C., Bouyssel, F., and de Rosnay, P.: From near-surface to root-zone soil moisture using different assimilation techniques, J. Hydrometeorology, 8, 194206, 2007.
Naeimi, V., Scipal, K., Bartalis, Z., Hasenauer, S., and Wagner, W.: An improved soil moisture retrieval algorithm for ERS and METOP scatterometer observations, IEEE Transactions on Geoscience and Remote Sensing, 47, 1999-2013, 2009.

Noilhan, J. and Mahfouf, J.-F.: The ISBA land surface parameterisation scheme, Global Planet. Change, 13, 145-159, 1996.

Noilhan, J. and Planton, S.: A simple parameterization of land surface processes for meteorological models, Mon. Weather Rev. 117, 536-549, 1989.

Owe, M., de Jeu, R., and Walker, J.: A methodology for surface soil moisture and vegetation optical depth retrieval using the microwave polarization difference index, IEEE Transactions on Geoscience and Remote Sensing, 39, 1643-1654, 2001.

Quintana-Seguí, P., Le Moigne, P., Durand, Y., Martin, E., Habets, F., Baillon, M., Canellas, C., Franchistéguy, L., and Morel, S.: Analysis of near-surface atmospheric variables: Validation of the SAFRAN analysis over France, J. Appl. Meteorol. Climatol., 47, 92-107, 2008.

Reichle, R. and Koster, R.: Bias reduction in short records of satellite soil moisture, Geophys. Res. Lett., 31, L19501, doi:10.1029/2004GL020938, 2004.

Reichle, R. and Koster, R.: Global assimilation of satellite surface soil moisture retrievals into the NASA Catchment Land Model, Geophys. Res. Lett., 32, L02404, doi:10.1029/2004GL021700, 2005.

Reichle, R., Koster, R., Dong, J., and Berg, A.: Global soil moisture from satellite observations, land surface models, and ground data: Implications for data assimilation, J. Hydrometeorology, 5, 430-442, 2004.

Thirel, G., Regimbeau, F., Martin, E., Noilhan, J., and Habets, F.: Short- and medium-range hydrological ensemble forecasts over France, Atmos. Sci. Lett., 11, 72-77, 2010.

van den Hurk, B., Ettema, J., and Viterbo, P.: Analysis of soil moisture changes in Europe during a single growing season in a new ECMWF soil moisture assimilation system, J. Hydrometeorology, 9, 116-131, 2008.

Vidal, J.-P., Martin, E., Franchistéguy, L., Baillon, M., and Soubeyroux, J.-M.: A 50-year high-resolution atmospheric reanalysis over France with the Safran system, Int. J. Climatol., 30, 1627 1644, 2010.

Wagner, W., Lemoine, G., and Rott, H.: A method for estimating soil moisture from ERS scatterometer and soil data, Remote Sens. Environ., 70, 191-207, 1999.

Wagner, W., Bartalis, Z., Naeimi, V., Park, S.-E., Figa-Saldaña, J., and Bonekamp, H.: Status of the MetOp ASCAT soil moisture product, 2010 International Geoscience and Remote Sensing Symposium, Proceedings, 2010. 